\title{
Cultural value in folktales and its representation in real cultural complexity: some personal remarks
}

\author{
Quang-Loc Nguyen \\ Ritsumeikan Asia Pacific University \\ Jumonjibaru, Beppu, Oita, 874-8577 Japan
}

February 23, 2021

Studying the induced meaning of folktales is a compelling field that catches great attention from scholars and anthropologists [1,2]. However, there are few in-depth investigations of each story's message related to the cultural behaviors $[3,4]$. Cultural additivity is a concept that significantly contributes to human understanding of how folktales induce cultural lessons to social behaviors [5]. In this paper, I attempt to comment the Cultural additivity: behavioural insights from the interaction of Confucianism, Buddhism and Taoism in folktales in terms of its used dataset construction, equation, modern world application, and limitation.

In the dataset construction, I wonder about the messages that the author give to the pattern of the action in each folktale. In the author's example, a husband violates the Three Moral Bonds. But what if he self-corrects or controls his attitude toward his wife after this behavior? For example, on day 1, the violation of Three Moral Bonds happens, so AVC (Anti-Confucian values) can be equivalent to 1 . However, on day 2, no violation of Three Moral Bonds happens, then AVC is equivalent to 0 . Thus, I believe that the dataset has not scoped the variation of characters' behaviors.

Furthermore, folktales often talk about a story with a limited number of characters. Thus, the folktale cannot show the pattern of behaviors and represent social values at a certain level. In reality, we may need to observe and collect more data on behaviors to show cultural influence and interaction. Therefore, I would recommend to the reader that the assumption would not be fully applied to the social context at the time.

In the societal implication of the paper, the author assumes: "While it might be true to claim that the three religions co-exist in a cultural entity, the empirical results allow us to make the case that there is more than just mere co-existence. There is indeed complex interaction and, seemingly, a domination of Confucianism over other religions". In this assumption, the data and equation are used to analyze based on the number of folktales rather than how much the influence of culture on real-life behavior, and differences between the unofficial culture and State's institutional culture professions, sciences. Therefore, the readers should be aware of how much difference between the folktales' and real-life' behaviors. This could help the readers interpret and apply the assumption more correctly.

In the modern world, young generations tend to pay less attention to folktales since they spend more time on the internet [6]. Besides, the migration of other religions and beliefs during globalization may have certain effects on cultural behaviors. Therefore, I think the paper is suited for those who are interested in history and certain cultural behaviors in a tech-saturated world [7].

Not only may the case of creating new folktales by individuals that not be relative to social circumstance [8], but also there is a significant number of outliers in studying social science. For example, Confucianism mentions loyalty to the king. In history, many people stand against the government (the king) due to many reasons, such as heavy levy. The parents' pious behaviour: 
there are examples of children on the news that behave 'disrespectfully' to their parents. And the virtuous attitude as a wife: there are stories of a wife cheated on her husband may raise the question of the truth. Therefore, I wonder how folktales' robustness influences people's behaviors: How much it influences, and at which scale? I hope in the next paper I can see some of the author's suggestions.

To sum up, the paper about cultural additivity [5] is a should-read paper for those studying history and cultural behaviors. This paper has attempted to remark its dataset structure, real-world application, and limitation. The limitation of the paper mainly derives from the finite representation of folktales to the real social complexity.

References

[1] Alberto Acerbi, Jeremy Kendal, and Jamshid J. Tehrani. (2017). Cultural complexity and demography: The case of folktales. Evolution and Human Behavior, 38(4), 474-480.

[2] John L. Fischer. (1963). The sociopsychological analysis of folktales. Current anthropology, 4(3), 235-295.

[3] Dennis Paul Klug. (1973). The significance of the Judeo-Christian-Black concept of man and history in values education. $\mathrm{PhD}$ Thesis, The Ohio State University.

[4] Quan-Hoang Vuong, et al. (2020). On how religions could accidentally incite lies and violence: folktales as a cultural transmitter. Palgrave Communications, 6(1), 82.

[5] Quan-Hoang Vuong, et al. (2018). Cultural additivity: behavioural insights from the interaction of Confucianism, Buddhism and Taoism in folktales. Palgrave Communications, 4(1), 143

[6] Trung Tran et al. (2020). How Digital Natives Learn and Thrive in the Digital Age: Evidence from an Emerging Economy. Sustainability 12(9) 3819.

[7] Richard M. Dorson. (2011). Folklore in the Modern World. Walter de Gruyter, 23.

[8] Satu Apo and David Hackston. (2007). The relationship between oral and literary tradition as a challenge in fairy-tale research: the case of Finnish folktales. Marvels Tales, 21(1), 19-33. 